\title{
Transfusion Requirements in Anemic Patients undergoing Cardiac Surgery
}

\author{
${ }^{1}$ Vaishali S Badge, ${ }^{2}$ Henry Skinner
}

\begin{abstract}
Cardiac surgery is one of the largest consumer of blood and blood products in medicine. The transfusion rate in cardiac surgery accounts to almost $40-90 \%$. Although lifesaving, it still increases the risk of allergic reactions, risk of transmission of infection, increased morbidity and mortality. The aim of this study was to find out causes of anaemia and requirement of blood or blood products in cardiac surgical patients.
\end{abstract}

Keywords: Anaemia, Blood transfusion.

How to cite this article: Badge VS, Skinner H. Transfusion Requirements in Anemic Patients undergoing Cardiac Surgery. Res Inno in Anesth 2017;2(1):26-27.

Source of support: Nil

Conflict of interest: None

\section{INTRODUCTION}

Preoperative anemia [hemoglobin $(\mathrm{Hb})<12 \mathrm{gm} \%$ ] has been associated with exposure to red blood cell (RBC) transfusion in cardiac surgical patients. ${ }^{1}$ We examined the correlation between preoperative $\mathrm{HB}$ and incidence of blood and blood product transfusion in the perioperative period in cardiac surgical patients in Trent Cardiac Centre, Nottingham, from April 2009 to June 2009.

This study was designed to demonstrate that low preoperative HB increases the chance for blood transfusion. This is proved by using chi-square test.

\section{MATERIALS AND METHODS}

This retrospective observational study examined 160 patients over 3 months from April 9 to June 9 undergoing cardiac surgeries. The patients were divided into two groups:

1. Group I: Patients with $\mathrm{Hb}>12 \mathrm{gm} \%$

2. Group II: Patients with $\mathrm{Hb}<12 \mathrm{gm} \%$

\footnotetext{
${ }^{1,2}$ Consultant Cardiac Anesthetist

${ }^{1}$ Department of Cardiac Anesthesiology, Apollo Hospitals, Navi Mumbai, Maharashtra, India

${ }^{2}$ Trent Cardiac Centre, Nottingham University Hospitals, NHS Trust, Nottingham, United Kingdom

Corresponding Author: Vaishali S Badge, Consultant Cardiac Anesthetist, Department of Cardiac Anesthesiology Apollo Hospitals, Navi Mumbai, Maharashtra, India, e-mail: drvaishali_b@apollohospitals.com
}

The analysis also involved

- Correlation of low preoperative HB and incidence of blood transfusion

- Preoperative HB and length of stay in cardiac intensive care unit (CICU)/hospital

- Investigations carried out to find the cause for anemia and treatment.

\section{RESULTS}

\section{Blood Transfusion}

There were 160 patients in this cohort. A total of 33\% $(n=53)$ of all patients received blood transfusion. In group II, $72 \%(n=21$ of 29$)$ of patients received blood transfusion. In group I, only $24 \%(n=32)$ of patients received blood in the perioperative period. This was statistically very significant $(\mathrm{p}<0.001$, chi-square test).

\section{Blood Product Transfusion}

It was observed that low preoperative $\mathrm{HB}$ increases the likelihood of receiving blood product transfusion as compared with patients with normal HB, as shown by chi-square test $(\mathrm{p}=0.006)$.

\section{Length of Stay}

We noticed that the length of stay in the CICU is increased in group II as compared with group I, although it is not statistically significant. About $62 \%$ of patients stayed for more than 3 days in group II in the ICU compared with $50 \%$ in group I (Graph 1).

\section{Investigations}

Out of 160 patients, 26 patients were investigated preoperatively, of which 14 patients were in group II, 12 were in group I. Most of these patients had gastrointestinal diseases causing anemia. However, all of them did not have anemia, and many of these patients were treated with either proton pump inhibitors or iron $\left(\mathrm{FeSO}_{4}\right)$, and few received blood transfusion.

\section{DISCUSSION}

In the United Kingdom, about half of the patients undergoing cardiac surgery receive blood transfusion. 


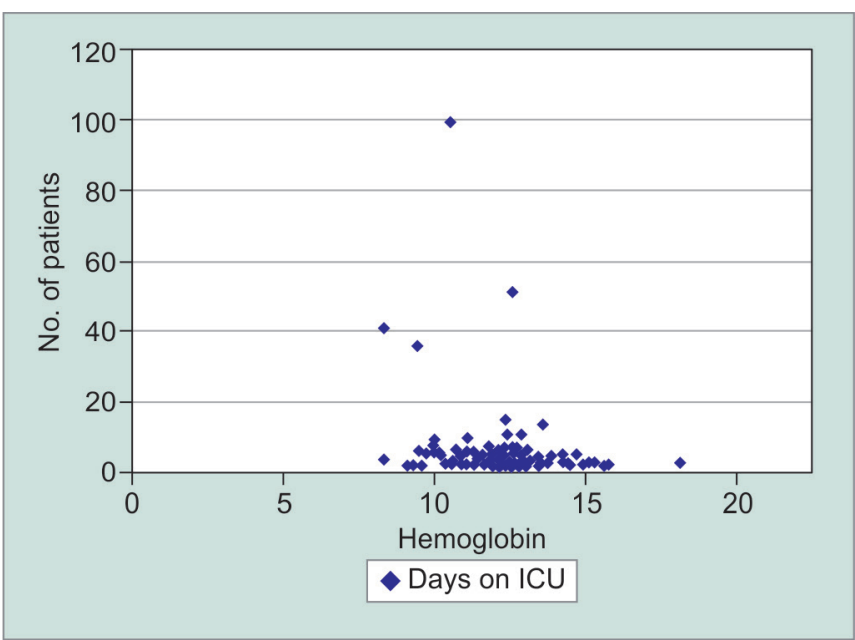

Graph 1: Observations

Transfusion has been associated with increased HB concentration and oxygen delivery. The proportion of patients receiving blood transfusion is high because of blood loss and severe anemia, which is associated with increased morbidity and mortality. Therefore, preoperative strategies should be able to detect and treat anemia, prevent excessive blood loss, and define optimal transfusion algorithm. The optimization of preoperative $\mathrm{HB}$ is important; hence, preoperative iron and erythropoietin therapy have been recommended. Iron deficiency has been shown to be responsible for preoperative anemia, followed by the presence of chronic kidney disease. ${ }^{2}$ Preoperative iron supplementation 3 to 5 weeks before surgery is recommended in patients with iron deficiency anemia, as it is beneficial compared with the risk of blood transfusion and its complications. The role of preoperative erythropoietin has not been proven in cardiac surgery due to increased incidence of thromboembolic complications. ${ }^{3}$

\section{CONCLUSION}

We observed that patients with low HB are at increased risk of blood transfusion.

However, it is also observed that all the patients with low HB were not investigated and treated preoperatively.

\section{RECOMMENDATIONS}

- It is important to actively investigate and treat preoperative anemia.

- In case of an emergency, consider treatment with intravenous iron, consult hematology.

- In elective cases, consider oral iron therapy and postpone surgery until anemia is corrected.

\section{REFERENCES}

1. Najafi M, Faraoni D. Hemoglobin optimization and transfusion strategies in patients undergoing cardiac surgery. World J Cardiol 2015 Jul;7(7):377-382.

2. Karski JM, Mathieu M, Cheng D, Carroll J, Scott GJ. Etiology of preoperative anemia in patients undergoing scheduled cardiac surgery. Can J Anaesth 1999 Oct;46(10): 979-982.

3. Cladellas M, Farré N, Comín-Colet J, Gómez M, Meroño O, Bosch MA, Vila J, Molera R, Segovia A, Bruguera J. Effects of preoperative intravenous erythropoietin plus iron on outcome in anemic patients after cardiac valve replacement. Am J Cardiol 2012 Oct;110(7):1021-1026. 
